\title{
Electric and Magnetic Fields from Return Stroke-Lateral Corona System and Red Sprites
}

\author{
Manoj Kumar Paras, Jagdish Rai \\ Department of Physics, Indian Institute of Technology Roorkee, Roorkee, India. \\ E-mail: mkparas.iitr@gmail.com \\ Received October 20 ${ }^{\text {th }}, 2011$; revised November $22^{\text {nd }}, 2011$; accepted November $30^{\text {th }}, 2011$.
}

\begin{abstract}
Electric and magnetic fields in time and frequency domain due to return stroke-lateral corona (RS-LC) system and recently discovered red sprites have been calculated. It has been found that the electric and magnetic fields due to return stroke and lateral corona system radiate in the very low frequency $(V L F)$ region while due to sprites radiate in the extremely low frequency (ELF) range. A comparison has been made between the radiation emitted due to $R S-L C$ system and sprites in ELF $(0-200 \mathrm{~Hz})$ region. It has been found that the electric field i.e. radiation power generated due to sprites dominates in the ELF range and thus it is concluded that the red sprites as compared to the RS-LC system are the prominent source for the excitation of Schumann resonances in the earth-ionosphere waveguide.
\end{abstract}

Keywords: Return Stroke, Lateral Corona, Lightning, Sprites, ELF, Ionosphere

\section{Introduction}

It is well known that thundercloud is generally the generator of all kind of lightning which occur in our atmosphere. Cloud-to-ground (CG) lightning, Intracloud lightning and recently discovered upper atmospheric lightning like red sprites, blue jets and elves are some kind of discharges which are associated directly or indirectly with the thunderclouds. We will not discuss in detail about blue jets and elves in this paper.

Sprites are diffuse to highly structured mesospheric discharges which occur at altitudes ranging from cloud tops to the ionosphere. R. C. Franz et al. [1] first detected the sprites by a low light level TV (LLLTV) camera. Latter D. D. Sentman et al. [2] gave strong evidences of the occurrence of sprites through airborne experiments. Sprites last from 5 to $100 \mathrm{~ms}$ [3] and generally occur in the form of clusters during the dying stage of the thunderstorm. Yu. P. Raizer et al. [4] considered the red sprites as long streamers originated from patches of enhanced ionization generated by EMPs from horizontal intracloud lightning. They can propagate upwards as well as downwards from their origination point [2]. Most of the sprites occur well after (up to tens of milliseconds) an associated lightning return stroke [3,5]. These long delayed sprites are associated to the strong continuing current moments $(>11 \mathrm{kA} \cdot \mathrm{km})$ from parent lightning [6]. Red sprites are manifestation of the breakdown of upper atmosphere due to the heating and ionization by the quasi-electrostatic fields developed at higher altitudes due to the large positive CG lightning [7]. These QE fields are linearly proportional to the vertical charge moment change (CMC) of the parent lightning discharge [4]. Another theory based on runaway electrons [8-10] describes that the cosmic ray electrons having energy $\left(\varepsilon_{c}\right.$ $\geq 0.1 \mathrm{MeV}$ ) can become runaway in presence of the quasi-electrostatic thundercloud electric field and bombard the upper atmosphere resulting in red sprites. Sprites can be generated by acoustic waves generated in the lower atmosphere due to natural cataclysms like hurricanes, thunderstorm lightning and tornados [11]. They have different shapes and sizes depending upon the causative positive cloud-to-ground lightning. The most common types are columnar shaped, carrot, angels, jellyfish, and A-bomb sprites [12].

Some workers $[13,14]$ have measured the radiation field from sprites and have mentioned that the field lies in the ELF region. However, the literature lacks in the case of frequency spectrum of electric and magnetic fields either obtained theoretically or experimentally. In this paper an attempt has been made to study theoreticcally the radiation electric and magnetic fields from sprites. In addition for the better understanding of some phenomena like Schuman resonances, these fields have been compared to the fields radiated by return stroke and 
lateral corona currents.

\section{Theory}

P. P. Pathak et al. [15] developed a theory to calculate the electric and magnetic fields due to arbitrary oriented lightning channel using an appropriate vector potential and taking the earth as a perfect conductor. Latter Divya and J. Rai [16] modified this theory and calculated the above fields by taking finite conductivity of earth into account. The general expression for a vector potential " $A$ " due to a current flowing in a lightning channel is given by

$$
A=\frac{\mu_{0}}{4 \pi} \int \frac{I\left(t^{\prime}\right)}{r} \mathrm{~d} z^{\prime}
$$

where, $\mu_{0}$ is the permeability of the free space; $r=\sqrt{D^{2}+h^{2}}$ is the distance between the observation point and the source, where $h$ is the vertical height of the lower base of the channel ( $h=0 \mathrm{~km}$ for RS-LC system and $h=50 \mathrm{~km}$ for red sprite) and $D$ is the horizontal distance measured from just below the channel base to the point of observation; $t^{\prime}(=t-r / c)$ is the retarded time; $\mathrm{d} z^{\prime}$ is the retarded elemental length of the channel; $I\left(t^{\prime}\right)$ is the current flowing in the channel.

Since $r$ is very large compared to the channel length, it can be taken outside the integration and we can break the vector potential into the time dependent and time independent parts. So " $A$ " can be written in the form

$$
A=\frac{\mu_{0}}{4 \pi r} A_{0} F\left(t^{\prime}\right)
$$

where, $A_{0}$ is a constant and $A_{0} F\left(t^{\prime}\right)=\int I\left(t^{\prime}\right) \mathrm{d} z^{\prime}$.

The waves emitted due to vector potential are reflected from the surface of the Earth and an image of the vector potential is formed. The image vector potential $A_{m}$ inside the conducting ground is given by

$$
\left|A_{m}\right|=R_{c}|A|
$$

where, $R_{c}=R_{v}$ for vertically polarized waves and $R_{c}=R_{h}$ for the horizontally polarized waves is the reflection coefficient given by

$$
\begin{aligned}
& R_{v}= \\
& \frac{\left[(\varepsilon+\sigma / i \omega) / \varepsilon_{0}\right] \cos \psi-\left[(\varepsilon+\sigma / i \omega) / \varepsilon_{0}-\sin ^{2} \psi\right]^{1 / 2}}{\left[(\varepsilon+\sigma / i \omega) / \varepsilon_{0}\right] \cos \psi+\left[(\varepsilon+\sigma / i \omega) / \varepsilon_{0}-\sin ^{2} \psi\right]^{1 / 2}} \\
& R_{h}=\frac{\cos \psi-\left[(\varepsilon+\sigma / i \omega) / \varepsilon_{0}-\sin ^{2} \psi\right]^{1 / 2}}{\cos \psi+\left[(\varepsilon+\sigma / i \omega) / \varepsilon_{0}-\sin ^{2} \psi\right]^{1 / 2}}
\end{aligned}
$$

where, $\psi=(\pi-\theta) ; \varepsilon=$ permittivity of the medium; $\varepsilon_{0}=$ permittivity of free space; $\sigma=$ ground conductivity; and $\omega$ is the angular frequency of the emitted wave.

Both $A$ and $A_{m}$ satisfy the Maxwell's equations. The electric and magnetic fields in spherical coordinates are given by

$$
\begin{gathered}
E\left(t^{\prime}\right)=\frac{A_{0}}{4 \pi \varepsilon_{0}}\left[k_{1} \int F\left(t^{\prime}\right) \mathrm{d} t+k_{2} F\left(t^{\prime}\right)+k_{3} \frac{\partial}{\partial t} F\left(t^{\prime}\right)\right] \\
H\left(t^{\prime}\right)=\frac{A_{0} f_{3}(\theta, \phi)}{4 \pi}\left[\frac{1}{r^{2}} F\left(t^{\prime}\right)+\frac{1}{r c} \frac{\partial}{\partial t} F\left(t^{\prime}\right)\right]
\end{gathered}
$$

where,

$$
\begin{gathered}
k_{1}=\frac{f_{1}(\theta, \phi)}{r^{3}} ; k_{2}=\frac{f_{1}(\theta, \phi)}{r^{2} c} ; k_{3}=\frac{f_{2}(\theta, \phi)}{r c^{2}} \\
f_{1}(\theta, \phi)=\cos \theta_{1}\left[2-\sin ^{2} \theta+\left(3 \sin ^{2} \theta-2\right) R_{v}\right] \\
-\left(3+R_{v}\right) \sin \theta_{1} \sin \theta \cos \theta \cos \left(\phi_{1}-\phi\right) \\
f_{2}(\theta, \phi)=\cos \theta_{1}\left(1+R_{v}\right) \sin ^{2} \theta \\
-\left(1-R_{v}\right) \sin \theta_{1} \cos \left(\phi_{1}-\phi\right) \sin \theta \cos \theta \\
f_{3}(\theta, \phi) \\
=\left[\left(1+R_{v}\right) \cos \theta_{1} \sin \theta-\left(1-R_{v}\right) \sin \theta_{1} \cos \theta \cos \left(\phi_{1}-\phi\right)\right]^{2} \\
\left.+\left[\left(1+R_{h}\right) \sin \theta_{1} \cos \theta \sin \left(\phi_{1}-\phi\right)\right]^{2}\right]^{1 / 2}
\end{gathered}
$$

where, $\left(r_{1}, \theta_{1}, \phi_{1}\right)$ is the orientation of the lightning channel from vertical and $(r, \theta, \phi)$ is the point of observation.

The first, second and third part of Equation (6) are called electrostatic $\left(E_{s}\right)$, induction $\left(E_{i}\right)$ and radiation $\left(E_{r}\right)$ electric fields respectively. Similarly in Equation (7) the first and second parts are induction $\left(H_{i}\right)$ and radiation $\left(H_{r}\right)$ magnetic fields respectively. Radiation fields developed by an antenna are much more significant as compared to other fields. It is the only field which can be measured at large distances and have long range effects.

In this paper we applied the above theory on RS-LC system and on the recently discovered mesospheric lightning "red sprites" and their electric and magnetic fields have been calculated in time as well as in frequency domain. Figure 1 shows the orientation of an arbitrary lightning channel in spherical-polar coordinates.

\section{Emissions from Return Stroke and Lateral Corona System}

The return stroke is the most intense form of cloudto-ground lightning and maximum current flows through it. L. B. Loeb [17] and J. Rai [18] have described the propagation of return stroke current using potential gradient waves. J. Rai [18] obtained the velocity and current expressions in time domain for the return stroke given by 


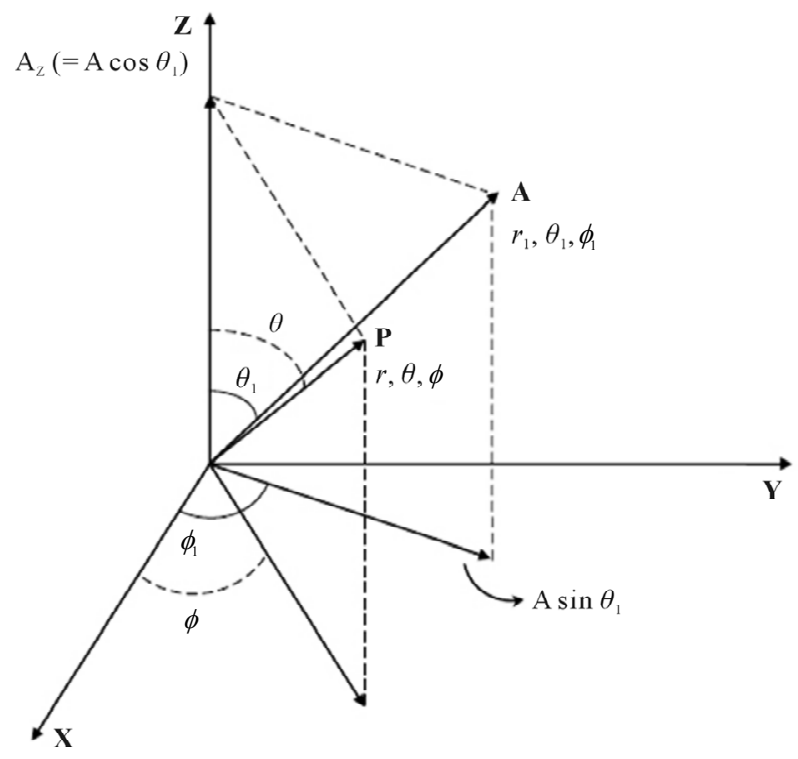

Figure 1. Schematic diagram shows the coordinate system used. $\mathrm{A}\left(r_{1}, \theta_{1}, \phi_{1}\right)$ and $\mathrm{P}(r, \theta, \phi)$ are the lightning position and observation point respectively. Here $r_{1} \approx 0$ as compare to $r$.

$$
\begin{aligned}
& V_{R S}(t)=V_{0}\left(\mathrm{e}^{-a t}-\mathrm{e}^{-b t}\right) \\
& I_{R S}(t)=I_{0}\left(\mathrm{e}^{-\alpha t}-\mathrm{e}^{-\beta t}\right)
\end{aligned}
$$

where, $V_{0}=9 \times 10^{7} \mathrm{~m} / \mathrm{s}, a=3 \times 10^{4} \mathrm{~s}^{-1}, \mathrm{~b}=7 \times 10^{5} \mathrm{~s}^{-1}$, $I_{0}=22 \mathrm{kA}, \alpha=1.6 \times 10^{4} \mathrm{~s}^{-1}$, and $\beta=5 \times 10^{5} \mathrm{~s}^{-1}$.

Below the tip of the return stroke, the whole channel up to ground surface is at ground potential, so the highly conducting core of the return stroke will attract the electrons and negative ions from the preionized medium left by stepped leader and constitute a current which immediately flows to the ground through this channel. Since this current is developed due to the radial movement of the negative ions and electrons, it is known as "lateral corona current". P. P. Pathak [19] gave the expression for the lateral corona current which is given by

$$
\begin{aligned}
I_{L C}(t)= & \frac{K V^{2} V_{0}}{a b}\left[(b-a) \exp \left(\frac{-2 t}{C R}\right)\right. \\
& \left.-b \exp \left[-\left(a+\frac{2}{C R}\right) t\right]+a \exp \left[-\left(b+\frac{2}{C R}\right) t\right]\right]
\end{aligned}
$$

where, $K=$ Corona constant $\left(10^{-16} \mathrm{AV}^{-2} \cdot \mathrm{m}^{-1} \cdot \mathrm{s}^{-1}\right) ; V=$ Potential difference between the return stroke and the leader sheath in volts and can be taken as $10^{8}$ Volts; $C=$ Distributed capacity of the leader sheath-return stroke core in farads $/ \mathrm{m} ; R=$ Distributed resistance of the above configuration $\left(C R=5.3865 \mathrm{~ms}\right.$ for $\left.I_{0}=22 \mathrm{kA}\right)$.

The total current flowing in the lightning channel can be written as

$$
I_{\text {Total }}(t)=I_{R S}(t)+I_{L C}(t)
$$

The calculated values of $A_{0}$ and $F\left(t^{\prime}\right)$ for the RS-LC system comes out to be

$$
\begin{gathered}
A_{0}=\frac{V_{0}}{a b} \\
F\left(t^{\prime}\right)=F_{1}\left(t^{\prime}\right) \times F_{2}\left(t^{\prime}\right)
\end{gathered}
$$

where,

$$
\begin{aligned}
& F_{1}\left(t^{\prime}\right)=I_{0}\left[\exp \left(-\alpha t^{\prime}\right)-\exp \left(-\beta t^{\prime}\right)\right] \\
& +i_{0}\left[(b-a) \exp \left(\frac{-2 t^{\prime}}{C R}\right)-b \exp \left[-\left(a+\frac{2}{C R}\right) t^{\prime}\right]\right. \\
& \left.+a \exp \left[-\left(b+\frac{2}{C R}\right) t^{\prime}\right]\right] \\
& F_{2}\left(t^{\prime}\right)=\left[a \exp \left(-b t^{\prime}\right)-b \exp \left(-a t^{\prime}\right)+(b-a)\right] \\
& i_{0}=\frac{K V^{2} V_{0}}{a b}
\end{aligned}
$$

Since RS-LC system is vertical, i.e. $\theta_{1}=0$ and $\theta=90$ at an observation point on the ground from the return stroke channel. $R_{v}=1$ for this system and the values of $f_{1}(\theta, \phi), f_{2}(\theta, \phi)$, and $f_{3}(\theta, \phi)$ can be found. So, $f_{1}=f_{2}=f_{3}$ $=2$. Using the values of $f_{1}, f_{2}, f_{3}$ and $R_{v}$ the Equations (6) and (7) become

$$
\begin{gathered}
E\left(t^{\prime}\right)=\frac{2 A_{0}}{4 \pi \varepsilon_{0}}\left[\frac{1}{r^{3}} \int F\left(t^{\prime}\right) \mathrm{d} t+\frac{1}{r^{2} c} F\left(t^{\prime}\right)+\frac{1}{r c^{2}} \frac{\partial}{\partial t} F\left(t^{\prime}\right)\right] \\
H\left(t^{\prime}\right)=\frac{2 A_{0}}{4 \pi}\left[\frac{1}{r^{2}} F\left(t^{\prime}\right)+\frac{1}{r c} \frac{\partial}{\partial t} F\left(t^{\prime}\right)\right]
\end{gathered}
$$

Using (14) and (15) the electric and magnetic fields in time domain have been calculated and shown in Figures 2 and 3 respectively. Electric fields due to RS-LC system at distances more than about $100 \mathrm{~km}$ behave purely in radiation form. Both electric and magnetic fields get peak very quickly at around $5 \mu$ s and then decay. Y. T. Lin et al. [20] measured the electric fields due to return strokes and found the zero axis crossing time in a range of 30 $60 \mu \mathrm{s}$. Our calculation gives a value of zero axis crossing time of $47 \mu$ shich is in conformity with his experimental observations. In addition both electric and magnetic fields in logarithmic time scale also have been shown in Figures $\mathbf{4}$ and $\mathbf{5}$ respectively to show the negative maxima. The negative maxima of low magnitude fall at around $84 \mu \mathrm{s}$. As the distance " $r$ " increases the magnitude of primary maxima decreases significantly but the negative maxima does not get any change. 


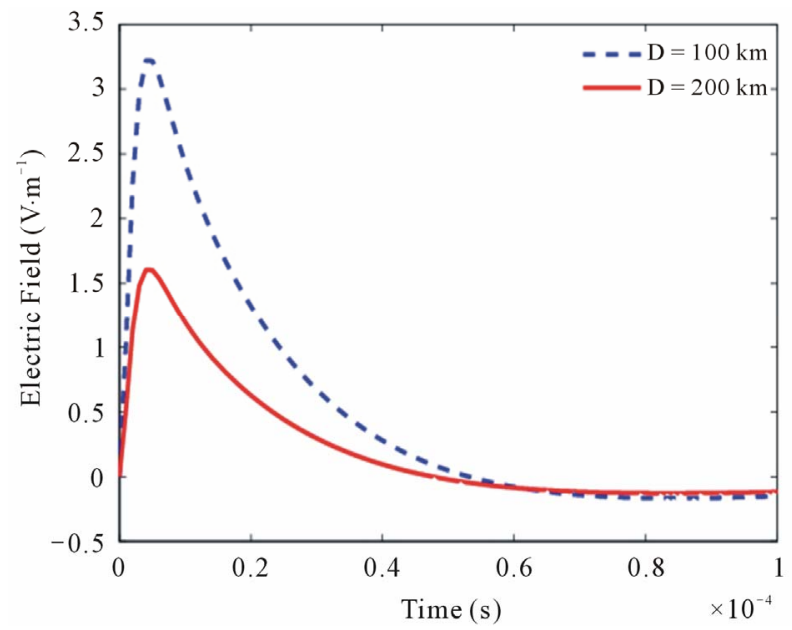

Figure 2. Total vertical electric field due to RS-LC system versus time. Electric field peaks at $5 \mu \mathrm{s}$.

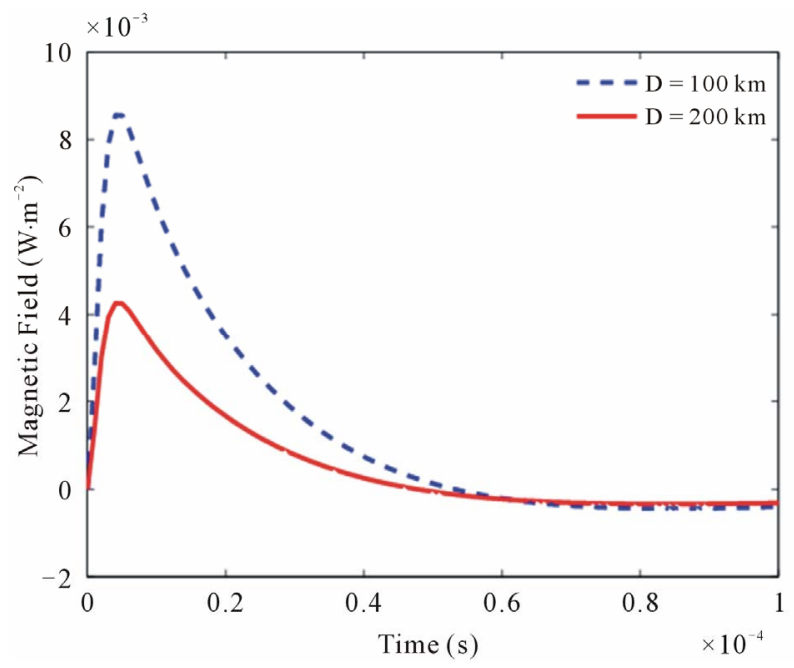

Figure 3. Total magnetic field versus time.

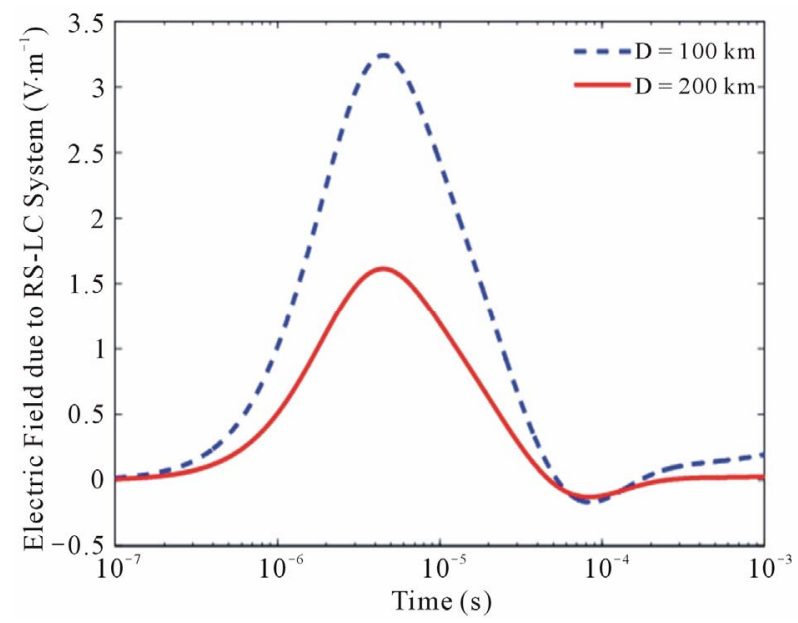

Figure 4. Total electric field from RS-LC system versus logarithmic time.

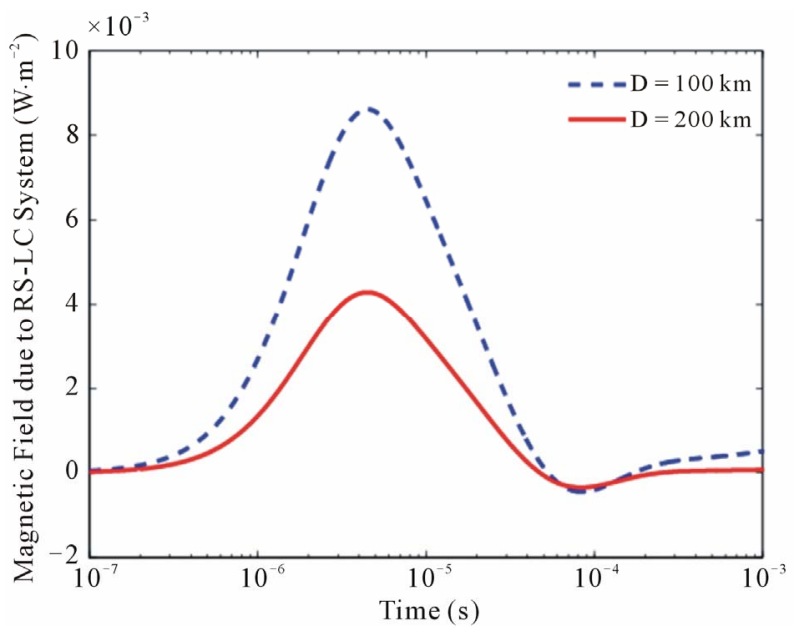

Figure 5. Total magnetic field from RS-LC system versus logarithmic time.

The electric and magnetic fields have been converted in frequency domain using the Fourier transformation technique. The fields in time domain can be converted into frequency domain using the standard equation given by

$$
f(\omega)=\int_{t^{\prime}=0}^{\infty} f\left(t^{\prime}\right) \mathrm{e}^{-i \omega t^{\prime}} \mathrm{d} t^{\prime}
$$

where, $f\left(t^{\prime}\right)$ and $f(\omega)$ are the electric or magnetic field in time and frequency domains respectively. Electric and magnetic fields due to RS-LC system in frequency domain have been shown in Figures 6 and 7 respectively. The radiation fields peak at around $5 \mathrm{kHz}$. The peak in magnetic field lies at the same frequency. The radiation field becomes dominant at distances of $100 \mathrm{~km}$ and above and hence the peak frequency for electric and magnetic field would coincide. However, the frequency to peak increases with increasing distance as the wave propagates in the earth-ionosphere waveguide where the attenuation is maximum at about $2 \mathrm{kHz}$ and decreases with increasing frequency. The peak shifts to about 11 $\mathrm{kHz}$ for distances of about $2000 \mathrm{~km}$.

\section{Emissions from Red Sprites}

Red sprites are upper atmospheric lightning discharges above thunderstorms and occur at altitudes ranging from cloud top to as high as $90 \mathrm{~km}$ having transverse extents of $\sim 10-50 \mathrm{~km}[2,21]$. It has been found that sprites are associated with strong positive cloud-to-ground lightning having peak current of $20-160 \mathrm{kA}$ [3,22-26].

The duration of the sprites is few milliseconds (3 - 100 ms) [3] and occurs in the form of clusters during the dying stage of the thunderstorms. The main reason of the occurrence of sprites is the quasi-electrostatic fields generated in the upper atmosphere due to the strong $+\mathrm{CG}$ 


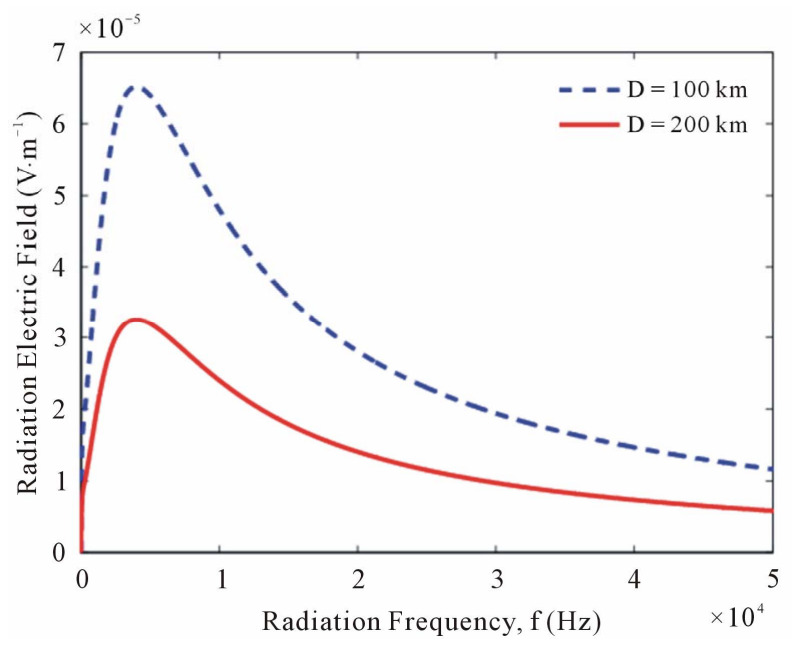

Figure 6. Vertical radiation electric field from RS-LC system versus frequency.

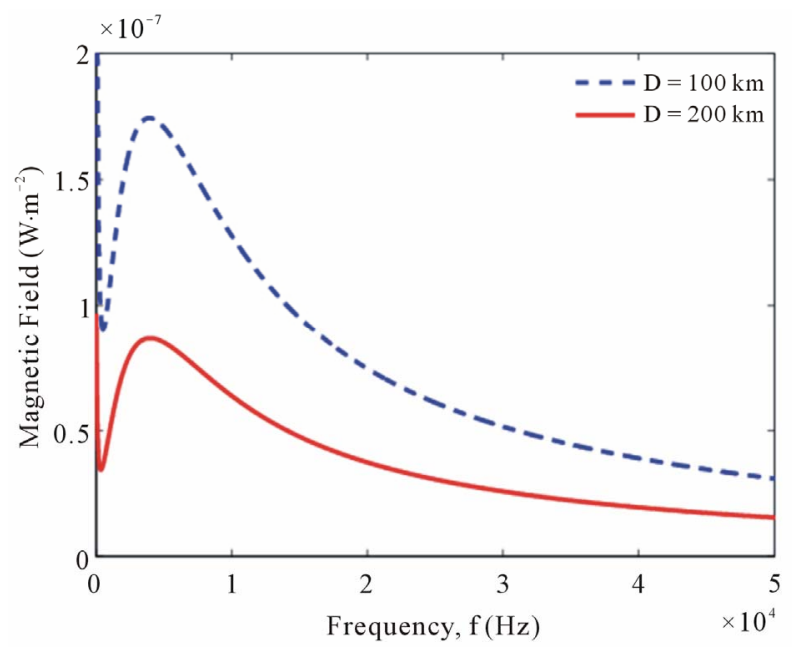

Figure 7. Total magnetic field from RS-LC system versus frequency.

discharges which produce heating, ionization, and runaway breakdown resulting in sprites [7,27]. Yu. P. Raizer et al. [4] described the propagation of sprites in the form of plasma streamers. J. Li. and S. A. Cummer [28] measured the peak velocities of these streamers in the range of $1-3 \times 10^{7} \mathrm{~ms}^{-1}$. The simulated velocity of sprites given by Yu. P. Raizer et al. [4] can be fitted in a Gaussian expression given by

$$
V_{S P}(t)=V_{1} \exp \left[-\xi(t-\eta)^{2}\right]
$$

where, $V_{1}=1.16 \times 10^{7} \mathrm{~ms}^{-1}, \eta=3.83 \times 10^{-3} \mathrm{~s}$ and $\xi=$ $4.13 \times 10^{5} \mathrm{~s}^{-2}$.

The above fitted curve for velocity has been shown in Figure 8 along with the simulation results of Yu. P. Raizer et al. [4].

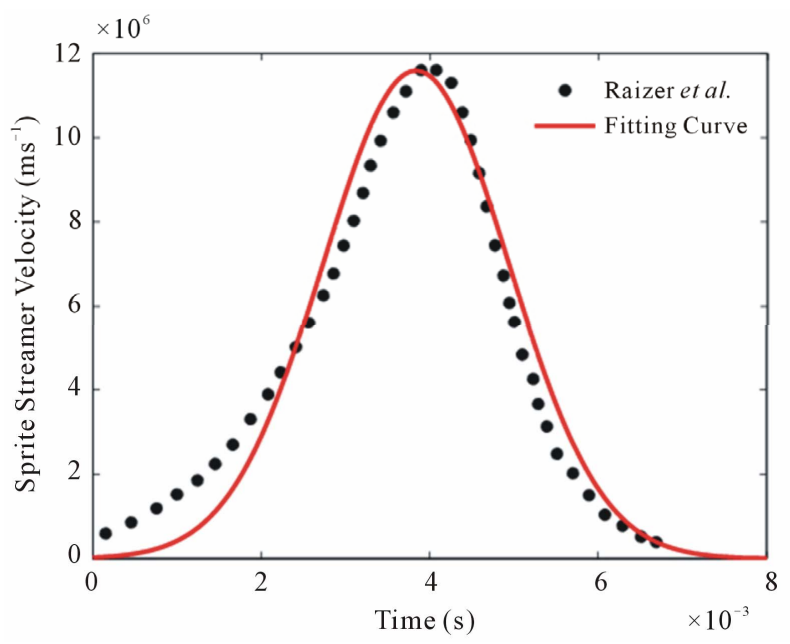

Figure 8. Sprite velocity versus time.

Further, some experimental values of sprite currents are available in the literature. S. A. Cummer et al. [13] first measured the electrical current flowing in the body of sprites. N. Liu [29] described the current increases as the sprites propagate with expansion, acceleration and brightening and vice versa. The peak vertical sprite current ranges from $1.6-3.3 \mathrm{kA} \mathrm{[13],} \mathrm{and} 5-10 \mathrm{kA}$ [30]. These electric currents produce the current moment which is responsible for the generation of electric and magnetic fields. The sprite current can be written by

$$
I_{S P}(t)=A \sigma(t) E(t)
$$

where, $\mathrm{A} \approx 400 \mathrm{~km}^{2}$ is the area of cross section in which current flows; $\sigma(t)$ is the ambient conductivity ahead of the propagating front of the sprite channel; and $E(t)$ is the electric field at the tip of the channel.

The sprite generating electric field using the simple point charge model [31] is given by

$$
E(t)=E_{0} \frac{\mathrm{e}^{-t / \tau_{q}}-\mathrm{e}^{-t / \tau_{r}}}{\tau_{q} / \tau_{r}-1}
$$

where,

$$
E_{0}=\frac{-1}{4 \pi \varepsilon_{0}} \frac{Q_{0}}{r^{2}}
$$

$E_{0}$ is the static Coulomb field; $Q_{0}=200 \mathrm{C}$, the charge removed by the $+\mathrm{CG}$ lightning; $r \approx 10 \mathrm{~km}$ the radial distance from the point charge; $\tau_{q}=10 \mathrm{~ms}$ the duration of the lightning current; and $\tau_{r}=\varepsilon_{0} / \sigma(z)$ is the relaxation time of the electric field.

The ambient electrical conductivity ahead of the streamer front [31] is given by

$$
\sigma(z)=\sigma_{0} \mathrm{e}^{\left(z-z_{0}\right) / s}
$$

where, $\sigma_{0} \approx 6.4 \times 10^{-10} \mathrm{~S} / \mathrm{m} ; z_{0}=50 \mathrm{~km} ;$ and $s=3.2 \mathrm{~km}$ 
describe the conductivity gradient in the earth's atmosphere. The altitude $\mathrm{z}$ of the propagating front of the sprite channel can be written as

$$
z=z_{0}+\int_{0}^{t} V(t) \mathrm{d} t
$$

Using Equations (17)-(21) the calculated current flowing in the body of sprites comes out to be double exponential form as for a return stroke but it varies very slowly as compared to the return stroke current. The calculated and double exponential currents for sprites are given in Figure 9. As an approximation the expression for the sprite current can be written by

$$
I_{S P}(t)=I_{1}\left(\mathrm{e}^{-\gamma t}-\mathrm{e}^{-\delta t}\right)
$$

where, $\gamma\left(1.10 \times 10^{2} \mathrm{~s}^{-1}\right)$ and $\delta\left(7.00 \times 10^{2} \mathrm{~s}^{-1}\right)$ are constants and the constant $I_{1}$ is taken into account the peak current of sprite.

From Equations (2), (17) and (22) we obtain

$$
\begin{gathered}
A_{0}=\frac{I_{1} V_{1}}{2} \sqrt{\frac{\pi}{\zeta}} \\
F\left(t^{\prime}\right)=\operatorname{erf}(\eta \sqrt{\zeta})\left[\exp \left(-\gamma t^{\prime}\right)-\exp \left(-\delta t^{\prime}\right)\right] \\
+\operatorname{erf}\left[\sqrt{\zeta}\left(t^{\prime}-\eta\right)\right]\left[\exp \left(-\gamma t^{\prime}\right)-\exp \left(-\delta t^{\prime}\right)\right]
\end{gathered}
$$

where,

$$
\operatorname{erf}(z)=\frac{2}{\sqrt{\pi}} \int_{0}^{Z} \mathrm{e}^{-u^{2}} \mathrm{~d} u \text { is error function }
$$

The calculated both total electric field and radiation electric field in time domain have been shown in Figures 10 and 11 respectively. Total magnetic field in time domain also has been shown in Figure 12. Both electric and magnetic fields due to red sprites in time domain

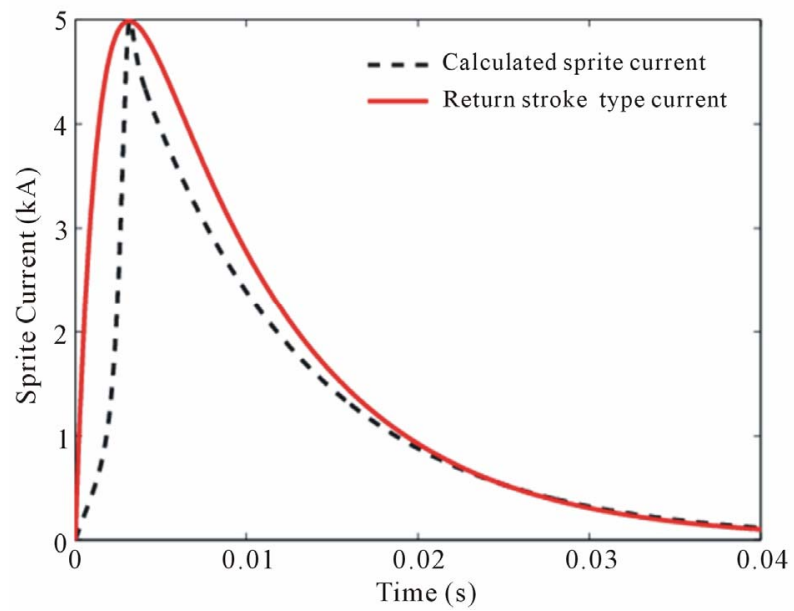

Figure 9. Sprite current versus time.

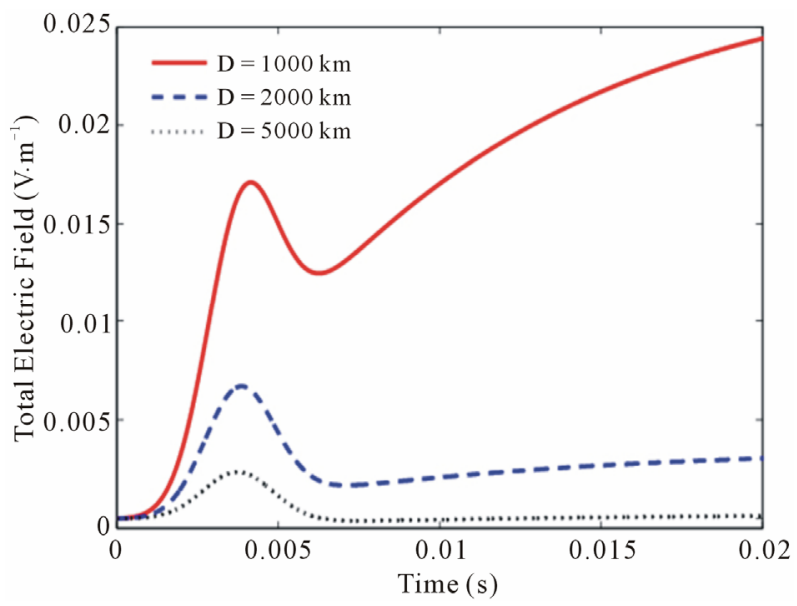

Figure 10. Total electric field from red sprites versus time at different distances of observation.

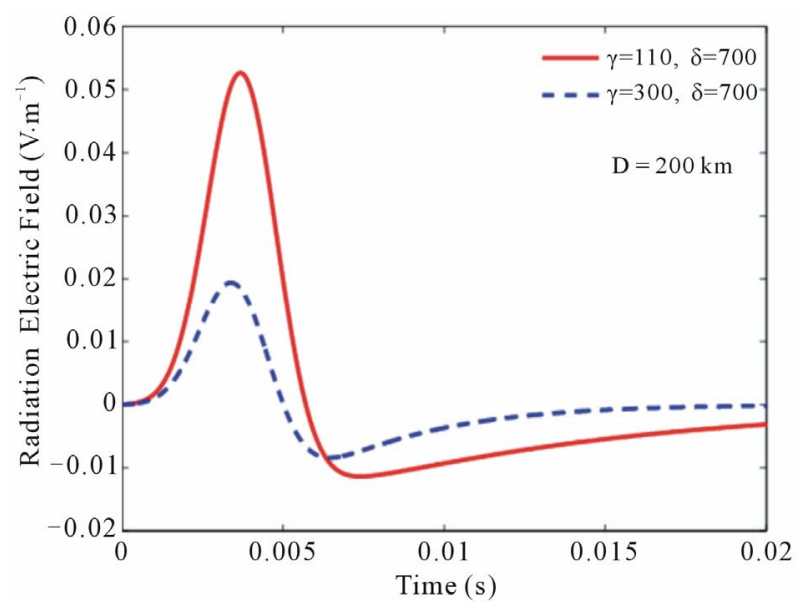

Figure 11. Radiation electric field due to red sprites versus time at a distance of $200 \mathrm{~km}$ from the channel in which current is flowing.

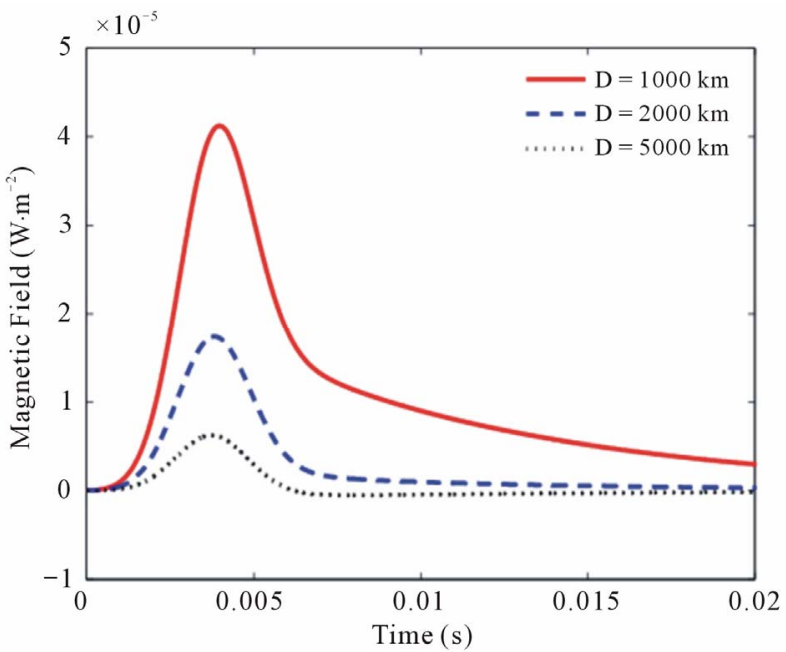

Figure 12. Total magnetic field from sprites versus time. 
get peak at around $3.70 \mathrm{~ms}$ for $\gamma\left(=1.10 \times 10^{2} \mathrm{~s}^{-1}\right)$. Peak shifts towards lower time with increasing $\gamma$ and taking $\delta$ $\left(=7.00 \times 10^{2} \mathrm{~s}^{-1}\right)$ as constant. The zero axis crossing time of radiation electric and magnetic fields ranges from 4.47 $5.75 \mathrm{~ms}$ as $\gamma$ varies from $6.00 \times 10^{2}$ to $1.00 \times 10^{2} \mathrm{~s}^{-1}$. In addition both radiation electric and magnetic fields versus logarithmic time scale also have been shown in Figures 13 and 14 respectively to show the negative maxima. In this case negative maxima fall at around $7 \mathrm{~ms}$ for $\gamma=$ $1.10 \times 10^{2} \mathrm{~s}^{-1}$. As the value of $\gamma$ increases the magnitude of primary maxima decreases but the magnitude of negative maxima do not affect that much, rather it shifts towards lower values of time.

Using Equation (16), the Fourier transforms of these electric and magnetic fields have been obtained and shown in Figures 15 and 16 respectively. It is concluded that the peak value of both electric and magnetic fields

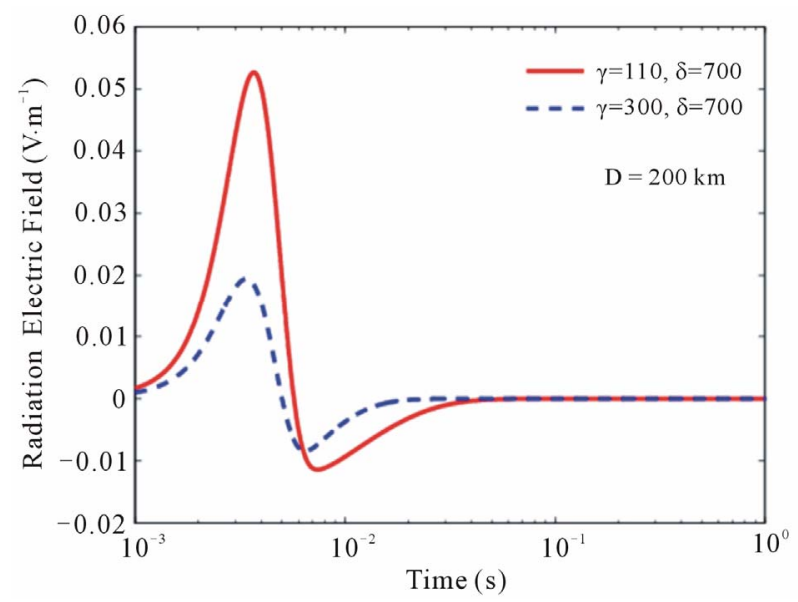

Figure 13. Radiation electric field from sprites versus time in logarithmic scale.

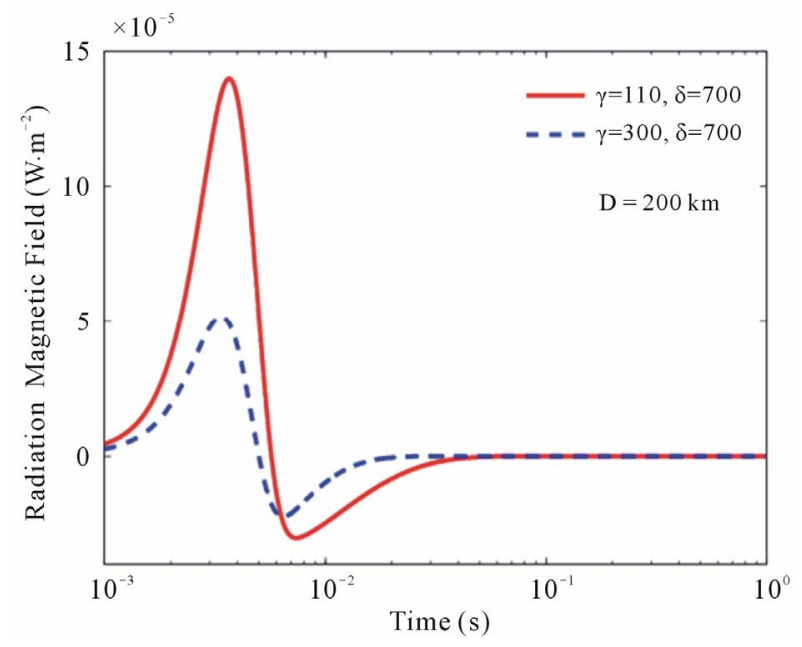

Figure 14. Radiation magnetic field from sprites versus time in logarithmic scale.

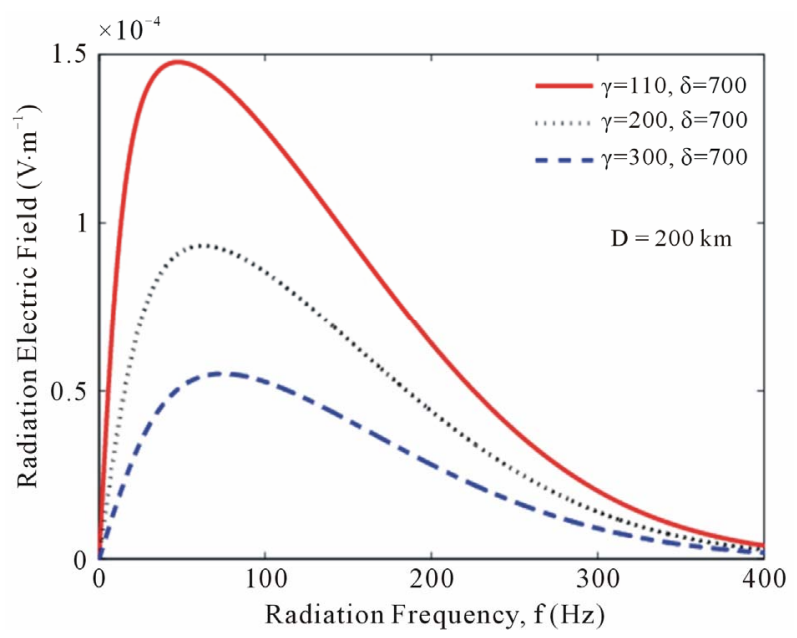

Figure 15. Radiation electric field in frequency domain due to red sprites at a distance of $200 \mathbf{~ k m}$ from the channel.

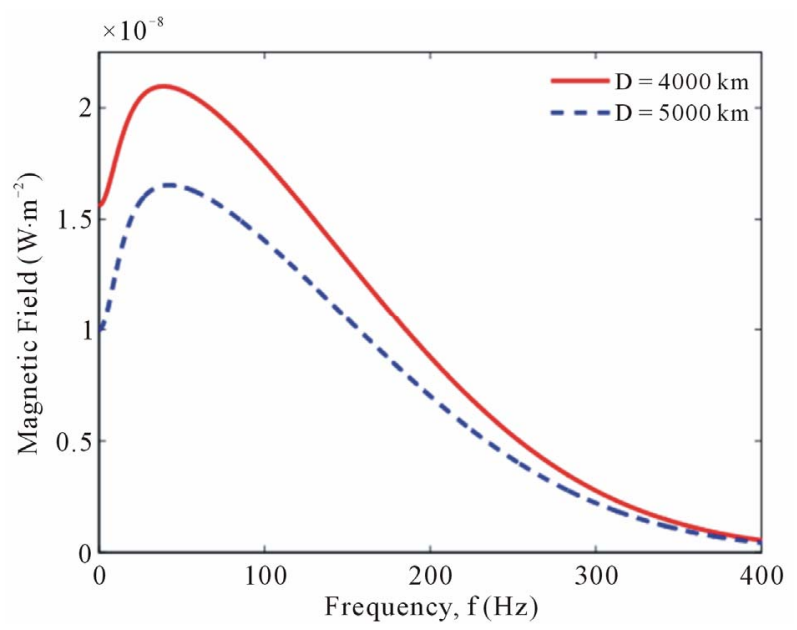

Figure 16. Total magnetic field due to red sprite versus frequency.

due to red sprites shifts towards the higher frequencies for larger values of $\gamma$ and lie in the ELF region. S. C. Reising et al. [3] showed experimentally that the emission from sprites lies in the ELF region. Further experiments have shown that the radiation electric fields are essentially in ELF range $[13,14]$. The radiation electric field is a function of current parameter $\gamma$. With increasing values of $\gamma$ the frequency to peak electric field increases. However, the peak amplitude has an opposite effect. The value to peak electric field is higher for lower values of $\gamma$.

\section{Radiation Fields Due to RS-LC System and Red Sprites in ELF Region}

A comparison between radiation electric and magnetic fields due to RS-LC system and red sprites in ELF region has been done. Both the radiation electric and magnetic fields due to red sprite at $200 \mathrm{~km}$ from the source domi- 
nate over RS-LC system. The comparison between radiation electric and magnetic fields due to RS-LC system and red sprite have been shown in Figures 17 and 18 respectively.

The electric and magnetic fields in the ELF range at 20 $\mathrm{Hz}$ from red sprites are more than 40 times larger than that due to RS-LC system. Further the radiated power from these discharges can be computed for the sake of comparison. It can be calculated from the knowledge of the electric field and can be written as [32].

$$
P(\omega)=\frac{|E(\omega)|^{2}}{120 \times \pi}
$$

where, $E(\omega)$ is the electric field at frequency " $\omega$ " and $P(\omega)$ is the radiated power. The radiated powers for both red sprites and RS-LC system have been shown in Figure 19. The power radiated below $100 \mathrm{~Hz}$ lies mainly due to the red sprites while that due to RS-LC system dominates above about $400 \mathrm{~Hz}$. It peaks at around $5 \mathrm{kHz}$. Thus the maximum power in the ELF range which is responsible for Schumann resonances is emitted from sprites.

\section{Results, Discussion and Conclusions}

Electric and magnetic fields generated due to the RS-LC system and red sprites in time and frequency domain have been calculated. Since, return stroke current and lateral corona current flow within the lightning channel simultaneously, although their duration is different, these are inseparable from each other. Therefore their combined effects have been taken into consideration.

Electric field generated due to the RS-LC system in time domain peaks at $5 \mu \mathrm{s}$. Y. T. Lin et al. [20] measured the electric fields due to return-stroke and found the peak

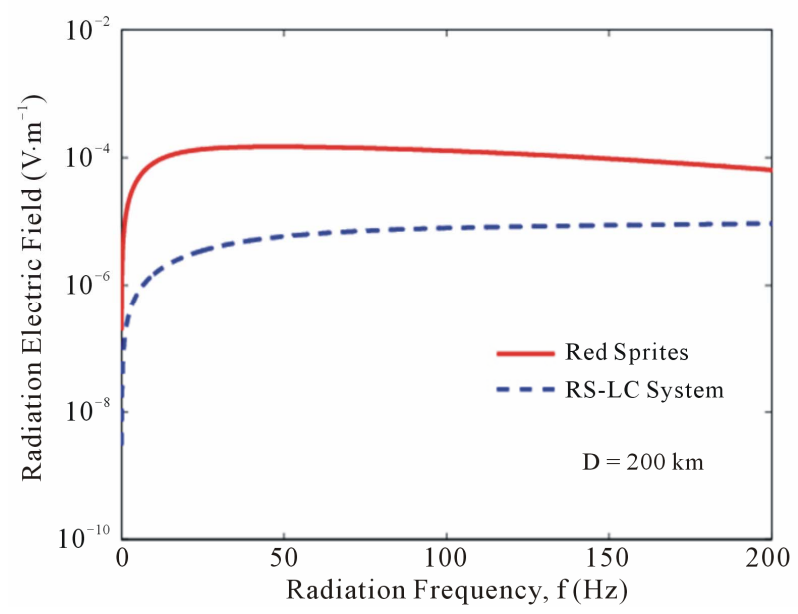

Figure 17. Radiation electric field due to RS-LC system and red sprite at $200 \mathrm{~km}$ from the source versus radiation frequency.

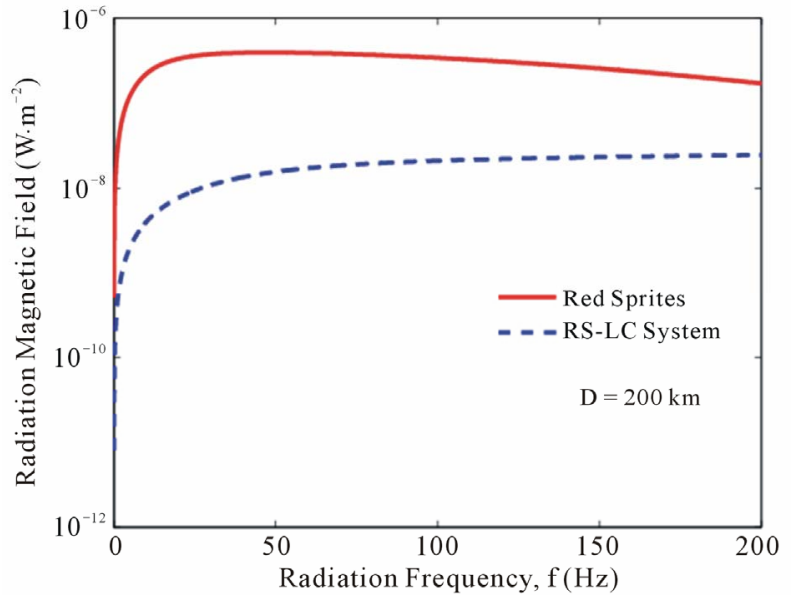

Figure 18. Radiation magnetic field due to RS-LC system and red sprite at $200 \mathrm{~km}$ from the source versus radiation frequency.

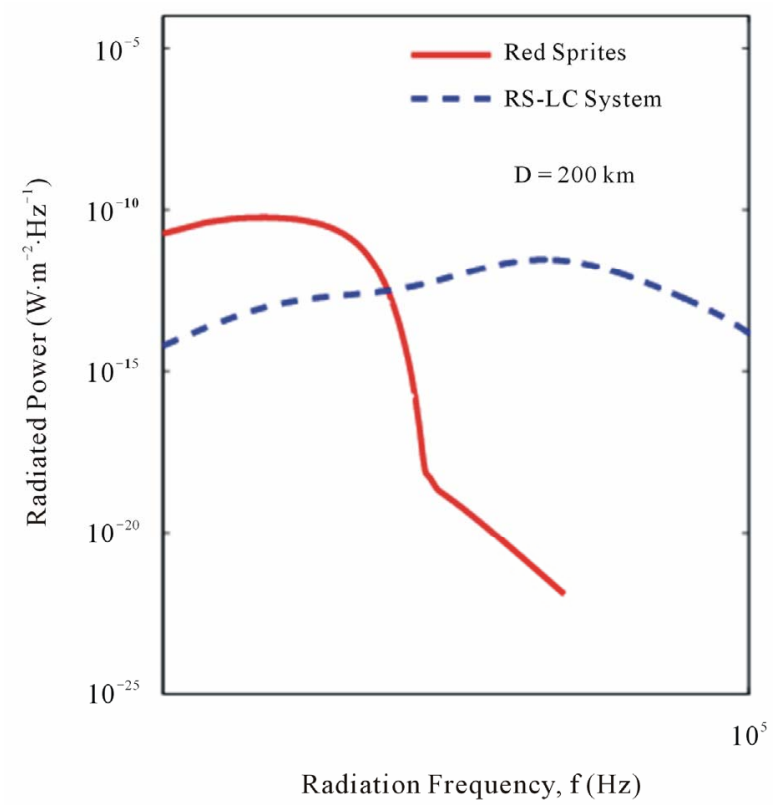

Figure 19. Radiated power due to red sprites and RS-LC system versus frequency.

at $5 \mu$ s. R. Moini et al. [33] calculated the electric and magnetic fields in time domain for different return-stroke models. In their calculation the electric and magnetic fields get peak very quickly $(\sim 1 \mu \mathrm{s})$. The basic model of return-stroke current was suggested by A. P. Nickolaenko and M. Hayakawa [34]. According to this model the return-stroke current peaks at around $5.5 \mu \mathrm{s}$ and then decays exponentially. The experimental measurements of electric fields due to return-stroke $[35,36]$ pertain to the peaks around $5 \mu \mathrm{s}$. The slowly varying lateral corona current may affect the electric and magnetic fields in the tail region of the waveform. The electromagnetic radia- 
tion generated by RS-LC system lie in the VLF range (3 $30 \mathrm{kHz}$ ). The electrical and magnetic fields peak at a frequency around $5 \mathrm{kHz}$. The experimental measurements [37] show that the return-stroke ground wave spectrum beyond $50 \mathrm{~km}$ peak near $4 \mathrm{kHz}$. Thus our calculation of the electric and magnetic fields due to RS-LC system is in confirmation with the other theoretical and experimental studies. The calculated electric and magnetic fields from red sprites peak at around $3.70 \mathrm{~ms}$ in time domain. The calculated radiation electric field generated by red sprites in frequency domain lie in the ELF range $(0-400 \mathrm{~Hz})$. S. A. Cummer et al. [13] reported the first experimental evidence of the ELF radiation produced by the electrical currents flowing in the body of sprites. S. C. Reising et al. [3] using experimental measurements described the ELF sferic energy as a proxy indicator for sprite occurrence. Thus our theoretical results are in conformity with the experimental observations. The peak of electric and magnetic fields in time as well as in frequency domain is strongly dependent on the parameters " $\alpha$ " and " $\gamma$ " in the cases of RS-LC system and sprites respectively. If the value of current parameter " $\alpha$ " is increased (taking " $\beta$ " as constant) the peak of electric and magnetic fields generated from RS-LC system shifts towards left i.e. lower values of time with decrement in their peak values. In frequency domain the peak shifts towards higher frequencies. Similar effects have been seen in the red sprite case. A good approach for further validation of our results would be the simulation studies. However, it is beyond the scope of this paper and would be taken separately.

The earth and ionosphere act as good electrical conductors at ELF and form a spherical earth-ionosphere waveguide. Among the various ELF radiators magnetic dipole is also a significant source of ELF radiations [38]. A detailed study of transverse electromagnetic (TEM) propagation constants like ELF attenuation rate, phase velocity and ionospheric reflection height for ELF daytime propagations in the earth-ionosphere waveguide has been done by P. R. Bannister [39]. A theoretical treatment of the excitation of the ELF pulses by lightning discharges in the earth-ionosphere waveguide has been made by A. I. Sukhorukov [40]. S. A. Cummer [41] and J. J. Simpson and A. Taflove [42] modeled the ELF propagation in the earth-ionosphere waveguide using a most efficient finite-difference time-domain (FDTD) algorithm. The waveguide parameters like the distance from the radiator and the effective reflecting heights from the ionosphere can be obtained through the delays of the waves reflected by the ionosphere with respect to the ground wave [43]. C. A. Valagiannopoulos and N. K. Uzunoglu [44] and C. A. Valagiannopoulos and N. K. Uzunoglu [45] described the propagation of ELF waves within the earth-ionosphere waveguide in a more general way by taking into account the variation of ionospheric height during the day to night time. In our case ELF radiation generated by RS-LC system and red sprites propagates within this earth ionosphere waveguide and associated electric and magnetic fields peak at the resonant frequencies of this cavity. The various ELF radiation excite the earth ionosphere cavity at frequencies between $3-60 \mathrm{~Hz}$ which are called Schumann resonances. Schumann resonances appear as distinct peak at ELF around 7.83, 14.3, 20.8, 27.3, and $33.8 \mathrm{~Hz}$ and so on both electric and magnetic field components. The calculated radiation electric and magnetic fields due to sprites at $20 \mathrm{~Hz}$ is more than 40 times stronger than the radiation fields due to RS-LC system at $200 \mathrm{~km}$ from the source. Thus it is concluded from the above calculations that the sprites may be the most prominent source for the excitation of Schumann resonances in the earth-ionosphere waveguide as compared to RS-LC system.

\section{Acknowledgements}

Author Manoj Kumar Paras is thankful to CSIR, New Delhi for their financial support. Authors are thankful to the referee for various suggestions.

\section{REFERENCES}

[1] R. C. Franz, R. J. Nemzek and J. R. Winckler, "Television Image of a Large upward Electric Discharge above a Thunderstorm System," Science, Vol. 249, No. 4964, 1990, pp. 48-51. doi:10.1126/science. 249.4964 .48

[2] D. D. Sentman, E. M. Wescott, D. L. Osborne, D. L. Hampton and M. J. Heavner, "Preliminary Results from the Sprites94 Campagion: Red Sprites," Geophysical Research Letters, Vol. 22, No. 10, 1995, pp. 1205-1208. doi:10.1029/95GL00583

[3] S. C. Reising, U. S. Inan and T. F. Bell, "ELF Sferic Energy as a Proxy Indicator for Sprite Occurrence," Geophysical Research Letters, Vol. 26, No. 7, 1999, pp. 987-990. doi:10.1029/1999GL900123

[4] Yu. P. Raizer, G. M. Milikh, M. N. Shneider and S. V. Novakovski, "Long Streamers in the Upper Atmosphere above Thundercloud," Journal of Physics D: Applied Physics, Vol. 31, No. 22, 1998, pp. 3255-3264. doi: $10.1088 / 0022-3727 / 31 / 22 / 014$

[5] T. F. Bell, S. C. Reising and U. S. Inan, "Intense Continuing Currents Following Positive Cloud-to-Ground Lightning Associated with Red Sprites," Geophysical Research Letters, Vol. 25, No. 8, 1998, pp. 1285-1288. doi:10.1029/98GL00734

[6] J. Li, S. A. Cummer, W. A. Lyons and T. E. Nelson, "Coordinated Analysis of Delayed Sprites with HighSpeed Images and Remote Electromagnetic Fields," Journal of Geophysical Research, Vol. 113, No. D20, 2008, pp. 1-11. doi:10.1029/2008JD010008

[7] V. P. Pasko, U. S. Inan, Y. N. Taranenko and T. F. Bell, 
"Sprites Produced by Quasi-Electrostatic Heating and Ionization in the Lower Ionosphere," Journal of Geophysical Research, Vol. 102, No. A3, 1997, pp. 45294561. doi:10.1029/96JA03528

[8] T. F. Bell, V. P. Pasko and U. S. Inan, "Runaway Electrons as a Source of Red Sprites in the Mesosphere," Geophysical Research Letters, Vol. 22, No. 16, 1995, pp. 2127-2130. doi:10.1029/95GL02239

[9] R. A. Roussel-Dupre and A. V. Gurevich, "On Runaway Breakdown and upward Propagating Discharges," Journal of Geophysical Research, Vol. 101, No. A2, 1996, pp. 2297-2311. doi:10.1029/95JA03278

[10] A. V. Gurevich and K. P. Zybin, "Runaway Breakdown and Electric Discharges in Thunderstorms," Physics-Uspekhi, Vol. 44, No. 11, 2001, pp. 1119-1140. doi:10.1070/PU2001v044n11ABEH000939

[11] A. R. Aramyan and G. A. Galechyan, "Formation of Red Sprites," Laser Physics, Vol. 19, No. 7, 2009, pp. 14801482. doi:10.1134/S1054660X09070196

[12] E. R. Williams, "Sprites, Elves, and Glow Discharge Tubes," Physics Today, Vol. 54, No. 11, 2001, pp. 41-47. doi:10.1063/1.1428435

[13] S. A. Cummer, U. S. Inan, T. F. Bell and C. P. Barrington-Leigh, "ELF Radiation Produced by Electrical Currents in Sprites," Geophysical Research Letters, Vol. 25, No. 8, 1998, pp. 1281-1284. doi:10.1029/98GL50937

[14] S. A. Cummer, "Current Moment in Sprite-Producing Lightning," Journal of Atmospheric and Solar-Terrestrial Physics, Vol. 65, No. 5, 2003, pp. 499-508. doi:10.1016/S1364-6826(02)00318-8

[15] P. P. Pathak, J. Rai and N. C. Varshneya, "VLF Radiation from Lightning," Geophysical Journal. Royal Astronomical Society, Vol. 69, 1982, pp. 197-207.

[16] Divya and J. Rai, "Calculation of Electric Fields from Lightning above Finitely Conducting Ground," Indian Journal of Radio and Space Physics, Vol. 15, 1986, p. 96.

[17] L. B. Loeb, "Confirmation and Extension of a Proposed Mechanism of the Stepped Leader Lightning Stroke," Journal of Geophysical Research, Vol. 73, No. 8, 1968, pp. 5813-5817. doi:10.1029/JB073i018p05813

[18] J. Rai, "Current and Velocity of the Return Stroke Lightning," Journal of Atmospheric and Terrestrial Physics, Vol. 40, No. 12, 1978, pp. 1275-1280. doi:10.1016/0021-9169(78)90078-8

[19] P. P. Pathak, "Some Studies on Lightning," Ph.D. Dissertation, University of Roorkee, Roorkee, 1982.

[20] Y. T. Lin, M. A. Uman, J. A. Tiller, R. D. Brantley, W. H. Beasley, E. P. Krider and C. D. Weidman, "Characterization of Lightning Return Stroke Electric and Magnetic Fields from Simultaneous Two Station Measurements," Journal of Geophysical Research, Vol. 84, No. C10, 1979, pp. 6307-6314. doi:10.1029/JC084iC10p06307

[21] W. A. Lyons, "Sprite Observations above the US High Plains in Relation to Their Parent Thunderstorm Systems," Journal of Geophysical Research, Vol. 101, No. D23, 1996, pp. 29641-29652. doi:10.1029/96JD01866
[22] D. J. Boccippio, E. R. Williams, S. J. Heckman, W. A. Lyons, I. Baker and R. Boldi, "Sprites, ELF Transients and Positive Ground Strokes," Science, Vol. 269, No. 5227, 1995, pp. 1088-1091. doi:10.1126/science. 269.5227 .1088

[23] S. C. Reising, U. S. Inan, T. F. Bell and W. A. Lyons, "Evidence for Continuing Current in Sprite-Producing Cloud-to-Ground-Lightning," Geophysical Research Letters, Vol. 23, No. 24, 1996, pp. 3639-3642. doi:10.1029/96GL03480

[24] E. Haung, E. Williams, R. Boldy, S. Heckman, W. Lyons, M. Taylor, T. Nelson and C. Wong, "Criteria for Sprites and Elves Based on Schumann Resonance Observations," Journal of Geophysical Research, Vol. 104, No. D14, 1999, pp. 16943-16964. doi:10.1029/1999JD900139

[25] C. Price, M. Asfur, W. A. Lyons and T. Nelson, "An Improved ELF/VLF Method for Globally Geolocating Sprite-Producing Lightning," Geophysical Research Letters, Vol. 29, No. 3, 2002, pp. 11-14. doi:10.1029/2001GL013519

[26] E. Williams, E. Downes, R. Boldy, W. Lyons and S. Heckman, "Polarity Asymmetry of Sprite-Producing Lightning: A Paradox?” Radio Science, Vol. 42, 2007, pp. 2-17. doi:10.1029/2006RS003488

[27] Y. Takahashi, A. Yoshida, M. Sato, T. Adachi, S. Kondo, R.-R. Hsu, H.-T. Su, A. B. Chen, S. B. Mende, H. U. Frey and L. C. Lee, "Absolute Optical Energy of Sprites and Its Relationship to Charge Moment of Parent Lightning Discharge Based on Measurement by ISUAL/AP," Journal of Geophysical Research, Vol. 115, 2010, Article ID: A00E55. doi:10.1029/2009JA014814

[28] J. Li. and S. A. Cummer, "Measurement of Sprite Streamer Acceleration and Deceleration," Geophysical Research Letters, Vol. 36, No. 10, 2009, pp. 1-5. doi:10.1029/2009GL037581

[29] N. Y. Liu, "Model of Sprite Luminous Trail Caused by Increasing Streamer Current," Geophysical Research Letters, Vol. 37, 2010, Article ID: L04102. doi:10.1029/2009GL042214

[30] M. J. Rycroft and A. Odzimek, "Effects of Lightning and Sprites on the Ionospheric Potential and Threshold Effects on Sprite Initiation, Obtained Using Analog Model of the Global Atmospheric Electric Circuit," Journal of Geophysical Research, Vol. 115, 2010, Article ID: A00E37. doi:10.1029/2009JA014758

[31] M. Fullekrug, "Elementary Model of Sprite Igniting Electric Fields," American Journal of Physical, Vol. 74, No. 9, 2006, pp. 804-805. doi:10.1119/1.2206573

[32] M. Garg, K. C. Mathpal, J. Rai and N. C. Varshneya, "Frequency Spectra of Electric and Magnetic Fields of Different Forms of Lightning," Annales Geophysicae, Vol. 38, 1982, pp. 177-188.

[33] R. Moini, B. Kordi, G. Z. Rafi and V. A. Rakov, "A New Lightning Return Stroke Model Based on Antenna Theory," Journal of Geophysical Research, Vol. 105, No. D24, 2000, pp. 29693-29702. doi:10.1029/2000JD900541

[34] A. P. Nickolaenko and M. Hayakawa, "Electric Fields 
Produced by Lightning Discharges," Journal of Geophysical Research, Vol. 103, No. D14, 1998, pp. 1717517189. doi:10.1029/98JD01163

[35] J. Rai, "Some Studies of Lightning Discharge and Radio Atmospherics," Ph.D. Dissertation, Banaras Hindu University, Varanashi, 1974.

[36] S. Hazarika, "Some Experimental Studies on Lightning and VLF Atmospherics)," Ph.D. Dissertation, University of Roorkee, Roorkee, 1987.

[37] G. I. Serhan, M. A. Uman, D. G. Childers and Y. T. Lin, "The RF Spectra of First and Subsequent Lightning Return Strokes in the 1 - $200 \mathrm{~km}$ Range," Radio Science, Vol. 15, No. 6, 1980, pp. 1089-1094. doi:10.1029/RS015i006p01089

[38] C. A. Valagiannopoulos and N. K. Uzunoglu, "Magnetic Dipole's Radiation in Plane Earth-Ionosphere Waveguide," Mediterranean Microwave Symposium, Athens, 6-8 September, 2005, pp. 65-70.

[39] P. R. Bannister, "Some Notes on ELF Earth-Ionosphere Waveguide Daytime Propagation Parameters," IEEE Transactions on Antennas and Propagations, Vol. AP-27, No. 5, 1979, pp. 696-698. doi:10.1109/TAP.1979.1142146

[40] A. I. Sukhorukov, "On the Excitation of the Earth-Ionosphere Waveguide by Pulsed ELF Sources," Journal of Atmospheric and Terrestrial Physics, Vol. 54, No. 10,
1992, pp. $1337-1345$. doi:10.1016/0021-9169(92)90043-K

[41] S. A. Cummer, "Modeling Electromagnetic Propagation in the Earth-Ionosphere Waveguide," IEEE Transactions on Antennas and Propagations, Vol. 48, No. 9, 2000, pp. 1420-1429. doi:10.1109/8.898776

[42] J. J. Simpson and A. Taflove, "Three-Dimensional FDTD Modeling of Impulsive ELF Propagation about the EarthSphere," IEEE Transactions on Antennas and Propagations, Vol. 52, No. 2, 2004, pp. 443-451. doi:10.1109/TAP.2004.823953

[43] Y. A. Krasnitsky, "Potential Accuracy of Estimation of Earth-Ionosphere Waveguide Parameters through Delays of Reflected Waves," Proceedings of the 10th International Conference RELIABILITY and STATISTICS in Transportation and Communication, Riga, 20-23 October 2010, pp. 374-378.

[44] C. A. Valagiannopoulos and N. K. Uzunoglu, "Scattering of ELF Waves by Underground Formations Because of Night-Day Ionosphere Ridge," Radio Science, Vol. 42, 2007, Article ID: RS6S32. doi:10.1029/2007RS003682

[45] C. A. Valagiannopoulos and N. K. Uzunoglu, "Simplified Model for EM Inverse Scattering by Longitudinal Subterranean Inhomogeneities Exploiting the Dawn/Dusk Ionospheric Ridge," IET Microwaves, Antennas \& Propagation, Vol. 5, No. 11, 2011, pp. 1319-1327. 